\title{
The Next Decade in Diagnostic Medicine Belong to Screening and Early Detection for Early Intervention \\ Anjan Bhattacharya*
}

Consultant Paediatrician, Child Development Centre, Apollo Gleneagles Hospital, Kolkata, India

Welcome to 2014. A new year is a new beginning. It brings with it promises of new modalities of diagnostic and interventional tools and strategies, all aiming at improving our existence in day to day living and functioning. Diseases and medical conditions seem to leap forward too, constantly outwitting us by a margin! But the fight must go on.

I take the example of the article of a fellow colleague, renowned in his own field of work, Multiple drug induced hypersensitivity syndrome reactions in a patient with drugs that have known HLA associations for reactions, a case report highlighting the need for preventative screening in modern medicine.

Prevention is better than cure! However clichéd the paraphrase is, it never fails to prove itself right in the face of never-ending challenges of effectively bringing the message home!

We seem to be conquering terrible diseases like cancer (however slowly) but we may not be doing enough yet to safeguard the preventable. In the clinical domain, we understand this with frustration! You may not know what you have been saved from!

That is why, there is a whole subject on Preventative Medicine and Health Management tools like Clinical Governance [1-4] in place.

But making prevention happen in real life, especially in settings where Dr. Khan and his colleagues are putting their high quality work, sometimes to be struck by the lack of consensus on agreed preventative principles in so called developing nations. This is where the burden of morbidity is monumental, both in terms of its sheer number as well as its magnitude resulting from various factors like lack of awareness, fear and cost implications!
Dr. Khan's institute has complex facilities and human resources for HLA-typing, hence much closure to pin-pointing an Allopurinol Hypersensitivity than simple clinical guess-work (and thus, source of debate and confusion). Yet, a lack of consensus prevents him from going ahead and does it before the medicine (otherwise designed to save) gets to take away (perhaps) the very life it was meant to salvage!

There are highly evolved Clinical Governance principles and strategies available at some part of this planet. All we need to do is to make the best use of our available resources. SWOT (Strength, Weakness, Opportunity, Strength) analysis shows that the challenge of Working Together can be turned to the opportunity of learning from this case report to pledge that we can at least consider doing HLA typing before we consider use of medication in our immediately future world, which has already landed on our door!

Which is why, I would like to see a large number of articles concentrating on Screening Tools as Early Detection modality of Diagnostic Medicine at this juncture of modern Diagnostic Medicine. Moreover, we should focus more on the broader term of Medicine as Health, both in its organic and non-organic entities, as some of us may be ready to vouch for their dual existence and importance in our lives!

\section{References}

1. www.dh.gov.uk.

2. www.gmc-uk.org.

3. www.rcpl.ac.uk.

4. Maity CK (2006) Medical Interviews and Professional Development: (2ndedn), Radcliffe Publishing (Oxford \& Seatle).
*Corresponding author: Anjan Bhattacharya, Consultant Paediatrician, Child Development Centre, Apollo Gleneagles Hospital, Kolkata, India, Tel: +919830032968; E-mail: anjanbhat@aol.com

Received January 04, 2014; Accepted January 07, 2014; Published January 09, 2014

Citation: Bhattacharya A (2014) The Next Decade in Diagnostic Medicine Belong to Screening and Early Detection for Early Intervention. Gen Med (Los Angel) 2: e107. doi: 10.4172/2327-5146.1000e107

Copyright: ( 2014 Bhattacharya A. This is an open-access article distributed under the terms of the Creative Commons Attribution License, which permits unrestricted use, distribution, and reproduction in any medium, provided the original author and source are credited. 